\title{
LA HOMOGENEIZACIÓN DEL PRESENTE: CONSCIENCIA GLOBAL Y TIEMPO DE LA HISTORIA EN CRÓNICAS SOBRE LA PRIMERA VUELTA AL MUNDO (1585-1601)
}

MIGUEL I. ARISTONDOa

\section{RESUMEN}

El presente artículo analiza narrativas sobre la expedición de Magallanes-Elcano a través de crónicas publicadas entre 1585 y 1601. La primera parte muestra cómo hacia finales del siglo XVI las referencias literarias y visuales a la nao Victoria enfatizaban una idea de ruptura entre el mundo moderno y la Antigüedad. La segunda parte examina cómo la Historia General... (1601) de Antonio de Herrera y Tordesillas entrelaza el relato de la primera vuelta al mundo con otros sucesos que tuvieron lugar en los inicios de la tercera década. El artículo muestra cómo las crónicas dieron una nueva forma a las tres categorías de presente, pasado y futuro al situar en el centro la experiencia de la primera vuelta al mundo como evento distintivo del tiempo presente. $\mathrm{Al}$ analizar la tensión que opera entre campo de experiencia y horizonte de expectativa, el presente trabajo sostiene que las crónicas de finales del siglo XVI narraron el evento de la primera vuelta al mundo como una experiencia de emancipación del tiempo presente en ruptura con el pasado.

PALABRAS CLAVE: crónicas, consciencia global, tiempo histórico, antiguos y modernos.

\section{HOMOGENIZING THE PRESENT: GLOBAL CONSCIOUSNESS AND HISTORICAL TIME IN CHRONICLES OF THE FIRST CIRCUMNAVIGATION OF THE WORLD (1585-1601)}

\begin{abstract}
This article analyzes narratives about the first circumnavigation of the world by focusing on chronicles published between 1585 and 1601. The first part shows how at the end of the $16^{\text {th }}$ century visual and literary references to the Nao Victoria emphasized the rupture between antiquity and the modern time. The second part examines how Antonio de Herrera y Tordesillas' Historia General... (1601) entangled histories about the first circumnavigation with other events at the beginning of the third decade. The article shows how chronicles reshaped the categories of past, present, and future by placing at the center the experience of circumnavigation in the present time. By analyzing the tension between space of experience and horizon of expectation, I argue

a Departamento de Literatura y Lenguas Romances, Universidad de Villanova, Filadelfia.

§ miguel.ibanezaristondo@villanova.edu
\end{abstract}


that late $16^{\text {th }}$ century chronicles narrated the first circumnavigation of the world as a present time emancipatory experience in rupture with the past.

KEY WORDS: chronicles, global consciousness, historical time, ancients and the moderns.

\section{INTRODUCCIÓN}

La primera vuelta al mundo iniciada en 1519 marcó el inicio de la primera globalización a nivel simbólico al realizarse por primera vez un viaje completo alrededor del globo. A través de las rutas oceánicas abiertas desde la península ibérica hacia el Nuevo Mundo, Asia y África, numerosos grupos comenzaron a interrelacionarse a través de una red que transformó modos de circular y comunicarse a escala planetaria. Hacia finales del siglo XVI, la imagen de la nao Victoria simbolizaba en crónicas y grabados la idea de advenimiento de un nuevo orden temporal asociado con los viajes transoceánicos y con la idea de que el globo había pasado a pertenecer a un orden de cosas humanas, medibles $y$ cuantificables. El presente artículo explora cómo las crónicas producidas en el periodo final del reinado de Felipe II proyectaban una nueva forma de escritura del tiempo en la historia al entrelazar el evento de la expedición de Magallanes-Elcano con otros sucesos relacionados con la expansión del mundo ibérico.

$\mathrm{Al}$ interrogarse sobre la experiencia del tiempo en la historia, François Hartog analizaba a través de la noción de régimes d'historicité las tensiones existentes entre campo de experiencia y horizonte de expectativa ${ }^{1}$. El historiador francés concebía el concepto de régime d'historicité como una herramienta heurística que ayuda a entender los momentos de crisis de tiempo en los que se pierden las referencias y evidencias sobre los modos de articular el pasado, el presente, y el futuro ${ }^{2}$. Descritas por Hannah Arendt como

\footnotetext{
Hartog, 2015. Regimes of historicity, presentism and experience of time. Columbia University Press, New York, p. 33. Los conceptos de campo de experiencia y horizonte de expectativa se derivan del trabajo de Reinhart Koselleck, que había previamente abordado la pregunta de cómo en cada presente las dimensiones temporales del pasado y del futuro habian estado siempre en estrecha relación. Ver en Koselleck, 1990. Le futur passé. Contribution à la sémantique des
}

brechas del tiempo, los momentos de crisis de tiempo designan rupturas que se dan en el terreno de la experiencia articulada a través de la historia. Según Hartog, hoy vivimos un momento marcado por el presentismo: el siglo XX, en retrospectiva, combina futurismo y presentismo. Comenzó más futurista que presentista, y terminó más presentista que futurista ${ }^{3}$.

Como afirma François Hartog, las sociedades occidentales están marcadas por el pasaje de una historia magistra vitae orientada al pasado, hacia una historia centrada en el futuro que comienza a escribirse hacia finales del siglo XVIII: el gran modelo historiográfico europeo, la historia magistra, sirvió durante siglos -hasta finales del siglo XVIII- para hacer el presente inteligible a través del pasado y de la fuerza de la ejemplaridad ${ }^{4}$. Para Hartog, la experiencia del Nuevo Mundo siguió vinculada a un modelo cristiano-providencialista que era solo inteligible a partir del pasado. Sin embargo, como ha observado Roberto Valdovinos, si bien los cronistas de Indias reproducen un modelo providencialista asentado en el pensamiento cristiano, la experiencia del Nuevo Mundo proyectó nuevos modos de articular el tiempo en la historia al entrar en conflicto con las múltiples formas de escribir el pasado de las sociedades de Indias ${ }^{5}$.

El contexto que emerge tras la primera vuelta al mundo abrió un horizonte de expectativa nuevo que hizo posible que el tiempo presente fuera narrado por los cronistas como un tiempo en ruptura con la Antigüedad. En lugar de ser inteligible a través del pasado, la emergencia de una consciencia global nueva aparece narrada

temps historiques, Editions de l'EHESS, Paris, capítulo 5, “'Champ d'expérience' et 'horizon d'attente': deux catégories historiques".

Hartog, 2015, op. cit., p. 45.

Ibidem, p. 107.

Ibidem, p. 74

Valdovinos, 2017. Un régime d'historicité face au Nouveau Monde, E-Spania: Revue électronique d'études hispaniques médiévales, 28. 
en las crónicas de finales del siglo XVI a partir de un campo de experiencia que solo puede remitir a las circunnavegaciones que tuvieron lugar en el presente. Al circunscribir el corpus a historias y producciones de finales del siglo XVI, el artículo explora cómo en un periodo en el que la circunnavegación del mundo había pasado a ser un tipo de experiencia posible, el evento de la primera vuelta al mundo era utilizado para expresar la emergencia de una consciencia global que, proyectada en múltiples narrativas e historias del siglo XVI, simbolizaba uno de los elementos distintivos del tiempo presente. Desde esa perspectiva, este trabajo sostiene que la posibilidad de rodear el mundo con las naos del mundo ibérico a partir de 1522 representaba en las crónicas un horizonte de expectativa nuevo que hizo posible articular un relato de emancipación de la historia en el presente.

En la Historia Natural y Moral de las Indias (1590) de José de Acosta y en la Historia General (1601) de Antonio de Herrera y Tordesillas, las referencias a la expedición de Magallanes-Elcano aparecen vinculadas a la idea de victoria sobre la redondez del mundo. Desde esa perspectiva, las conexiones que establecen las historias con la imagen de la nao Victoria no se fundamentaban únicamente en la nueva configuración espacial del mundo, sino en el valor simbólico que el evento tenía a la hora de definir la especificidad del tiempo presente. Más allá de postularse como narrativas que articulan una forma de homogeneización del espacio, el análisis de los relatos sobre la primera vuelta al mundo hacia finales del siglo XVI muestra que la emergencia de una consciencia global produjo una nueva forma de articular las tres categorías de presente, pasado y futuro en la historia.

LA NAO VICTORIA, SÍMBOLO DE UNA NUEVA TEMPORALIDAD

A diferencia de las relaciones que se publican y que circulan después de completarse el primer viaje alrededor del mundo, como De Moluccis Insulis (1523) de Maximiliano Transilvanus, y la Relazione del primo viaggio

6 Acosta, 2006. Historia Natural y Moral de las Indias. Edición de Edmundo O'Gorman, Fondo de Cultura intorno al mondo (1524-1525) de Antonio Pigafetta, las crónicas de Indias que se publican durante las últimas décadas del siglo XVI sitúan la expedición de Magallanes-Elcano dentro de un marco amplio de historias que se nutren entre sí, creando imágenes sobre la emergencia de una consciencia global vinculada al hecho de que el globo pudo y podía ser circunnavegado. Estas asociaciones no fueron fruto del primer periodo que siguió a la expedición de Magallanes-Elcano, sino que se fueron consolidando progresivamente y afirmándose en las crónicas como uno de los elementos que mejor definía un presente histórico en ruptura con el mundo antiguo. En la Historia Natural y Moral de las Indias, el jesuita José de Acosta asociaba la nao Victoria con las nuevas formas de representar el mundo en el terreno de la experiencia humana:

¿Quién dirá que la nao Victoria, digna cierto de perpetua memoria, no ganó la victoria y triunfo de la redondez del mundo- y, no menos, de aquel tan vano vacío y caos infinito que ponían los otros filósofos debajo de la tierra-pues dio la vuelta al mundo y rodeó la inmensidad del gran Océano? ¿A quién no le parecerá que, con este hecho, mostró que toda la grandeza de la tierra -por mayor que se pinte- está sujeta a los pies de un hombre, pues la pudo medir?6.

Para José de Acosta, la victoria del ser humano sobre la redondez del mundo recaía simbólicamente en la nao Victoria, la cual representaba lo que el jesuita consideraba el signo de un nuevo tiempo. Como observa Acosta, la primera circunnavegación que tiene como elemento simbólico la nao Victoria trascendía la historia al configurarse como elemento que simbolizaba un cambio profundo en las formas de representar el globo. La asociación que hace Acosta con la idea de una Antigüedad en declive comienza a cristalizar a finales del siglo XVI. Como observó Anthony Grafton, entre 1550 y 1650 los pensadores de Occidente dejaron de creer que podrian encontrar todas las verdades

Económica, México, p. 20. 
importantes en libros del mundo antiguo ${ }^{7}$. Esta idea es particularmente importante en el trabajo de José de Acosta, autor con el que Grafton iniciaba su trabajo sobre el impacto que tuvieron los descubrimientos en la redefinición de la tradición a través de autores y obras de la Antigüedad.

Las obras que se escriben durante la segunda mitad del siglo XVI y que narran la vuelta al mundo anuncian el distanciamiento del presente respecto a una Antigüedad que ya no podía ofrecer las referencias para articular la experiencia de circunnavegación. Como ha observado Louise Bénat-Tachot, la primera globalización en el mundo ibérico produce un tipo de consciencia global que tiene su origen en la expedición de Magallanes-Elcano y recorre gran parte del siglo XVI: a partir de 1519 y hasta 1579 se opera una etapa fundacional no solamente de los descubrimientos, sino también de la consciencia de los espacios terrestres y oceánicos ${ }^{8}$. Desde otra perspectiva, Roberto Valdovinos asocia los descubrimientos en el Nuevo Mundo con un cambio en el régimen de temporalidad en el siglo XVI que se constituye al cuestionarse los fundamentos del saber antiguo. Para Valdovinos, la etapa clave en la historia de la primera globalización tiene lugar entre la llegada de Hernán Cortés al Nuevo Mundo y la crónica de Francisco López de Gómara. Entre estos dos momentos, emerge una distancia que separa el presente histórico de la tradición clásica y bíblica. Como observa Valdovinos, la referencia de López de Gómara (1922) al viaje de la nao Victoria a través de toda la redondez de la tierra se asocia con un saber antiguo definido como deficiente:

Niegan todos los antiguos filósofos de la gentilidad el paso de nuestro hemisferio al de los antípodas, por razón de estar en medio la tórrida zona y el océano, que impiden el camino [...] Quiero dejar las muchas naos que ordinariamente van de España a las Indias, y decir de una sola, dicha la Victoria, que dio vuelta redonda a

7 Grafton, 1992. New Worlds, Ancient Texts: The Power of Tradition and the Shock of Discovery. Harvard University Press, Cambridge, p. 1.

8 Bénat-Tachot, 2018. Les tracés du monde: réflexions sur les voies d'une première globalisation 1519-1579, E-Spania: Revue électronique d'études hispaniques médiévales, 30, toda la redondez de la tierra, y tocando en tierras de unos y otros antípodas, declaró la ignorancia de la sabia antigüedad ${ }^{9}$.

En lugar de establecerse a través de la experiencia del Nuevo Mundo, la construcción de un discurso en torno a la ignorancia de la Antigüedad se asocia con la imagen de la nao Victoria y con la idea de "redondez" de la tierra enfatizada en el texto de López de Gómara: dar la vuelta redonda a toda la redondez de la tierra. Las imágenes asociadas con el control y dominio de la redondez de la esfera anuncian una nueva forma de escribir el presente respecto a un mundo antiguo percibido como deficiente. Además de las crónicas de Indias, la idea de control sobre la redondez la encontramos en misceláneas del periodo, donde la expansión marítima adquiere una connotación épica. En la Miscelánea Silva de casos curiosos de Luis Zapata de Chaves (1592), la actividad de contrastar las invenciones de antiguos y modernos representa el elemento principal de la narrativa. Al analizar joyas, tesoros, artes e invenciones, Zapata incluye entre los logros del mundo moderno la circunnavegación de la nao Victoria para concluir que el mundo moderno es superior a la Antigüedad:

¿Qué invención tan útil fue a toda la redondez de la tierra el descubrimiento de las Indias que hizo Don Cristóbal Colón? ¿Cuántas riquezas, cuántas cosas salutíferas se han traído de allá? Y del camino del infierno, ¿cuántas almas de indios ha vuelto esta invención para el cielo, que a causa de haberles predicado la fe han sido salvas? ¿Cuándo, como hoy, se vieron dos nortes? ¿Cuándo, como hoy, se supo ser habitable la tierra debajo de la linea equinoccial? ¿Cuándo, como hoy, se dio vuelta por mar a todo el orbe? Como Magallanes la rodeó con su nave, que se llamó Vitoria, en señal que con vitoria españoles han pasado y llegado allá ${ }^{10}$.

p. 9.

9 Valdovinos, 2017, op. cit., p. 20.

10 Zapata, 1931. Miscelánea: silva de casos curiosos. Compañía Ibero-Americana de Publicaciones, Madrid, $\mathrm{p}$. 124. 
En el compendio de invenciones del mundo moderno de Luis Zapata, la nao Victoria representa un signo de victoria a varios niveles: victoria sobre los mares océanos, victoria sobre la redondez del mundo y victoria sobre una Antigüedad en declive por el advenimiento de un mundo moderno que solo puede ser narrado en sus propios términos. En la Silva de casos curiosos de Zapata, la continua reivindicación del presente se opone a un sentimiento crítico y negativo: ¡Cuán enfadosa es la gala que tienen algunos de quejarse del tiempo y decir que los hombres de agora no son tan inventivos ni tan señalados, y que cada hora en esta va empeorando! Yo quiero, pues, volver por la honra de esta nuestra edad, y mostrar cuánto en invenciones y sotilezas al mundo de agora somos en cargo ${ }^{11}$. En la Silva de casos curiosos, narrar un presente triunfalista no solo suponía referir los eventos que tuvieron lugar durante el periodo de expansión del mundo ibérico, sino que también consistía en oponerse a un sentimiento de crisis de los proyectos expansionistas a finales del siglo XVI. En ese sentido, distinguir el mundo moderno como más grandioso que la Antigüedad reflejaba también la idea de pérdida por un periodo de expansión en el pasado reciente del siglo XVI.

Además del libro de Zapata, los grabados de Stradanus (Jan Van der Straet) en su Nova Reperta (ca. 1600) definen la distancia del presente con una Antigüedad en declive a partir de inventos y descubrimientos producidos por los modernos. En la ilustración que sirve de título a la serie de grabados (Fig. 1), vemos en la parte superior izquierda a una mujer desnuda apuntando con una vara a un mapa de América. En la parte derecha, un anciano simbolizando el mundo antiguo abandona la escena. Ambas figuras llevan una serpiente mordiéndose la cola, el ouroboros, que indica la circularidad del tiempo y la idea de principio y final de un ciclo. Debajo de la inscripción Nova Reperta (Nuevas Invenciones), vemos una imprenta con hojas colgando de una cuerda entre dos medallones

11 Ibidem, p. 122.

12 Entre los numerosos trabajos que analizan la serie de grabados de Stradanus, ver: Eisenstein, 2011. Divine Art, Infernal Machine. University of Pennsylvania Press, Philadelphia.

13 La primera edición del Parergon Sive Veteris Geographia con el dibujo de un compás, símbolo de la navegación, y el mapa de América, representando el descubrimiento de mundos desconocidos en la Antigüedad. Entre las palabras Nova Reperta, la imagen incluye el símbolo de la Cruz del Sur que remite a las exploraciones marítimas en el hemisferio sur y a la llegada del cristianismo a otras tierras $^{12}$.

En la serie de grabados de Nova Reperta, la circularidad del tiempo y la idea de final y principio de un nuevo orden temporal son proyectadas a partir de descubrimientos del mundo moderno. Los grabados de Nova Reperta proyectan una idea de ruptura respecto a un mundo antiguo que, si bien sigue sirviendo de modelo a la hora de definir el presente, ya no integra un campo de experiencia moderno en el que la navegación y el Nuevo Mundo ocupan un lugar central. La idea de distanciamiento de la Antigüedad aparece igualmente evocada en mapas producidos durante ese momento de crisis que emerge en el último tercio del siglo XVI. En el atlas del mundo antiguo (Parergon Sive Veteris Geographia), Abraham Ortelius incluye un mapa que corresponde con la geografía del mundo antiguo conocido sobre un molde cartográfico moderno, proyectando así la minúscula dimensión de la Antigüedad sobre un extenso mapa del mundo ${ }^{13}$.

Igualmente, en el mapa del Pacífico (fig. 2) publicado en 1590 en el Theatrum Orbis Terrarum de Abraham Ortelius, una imagen de la nao Victoria al inicio de su ruta transpacífica después de cruzar el estrecho de Magallanes simboliza la apertura de los mares a la navegación. Dentro de la nao vemos a la tripulación haciendo un saludo conmemorativo con el fuego de los cañones. En la proa, una imagen de la diosa griega Nike, símbolo de la victoria militar, indica el camino que separa la América meridional del sudeste asiático. Debajo de la nave, un verso en latín hace referencia a la victoria sobre los mares: Fui la primera en navegar alrededor del mundo a vela, y te llevé a ti primero, Magallanes, a través del estrecho. Navegué por todo el mundo, por

(1579) contiene solo tres mapas. Durante los siguientes años Ortelius fue añadiendo mapas hasta completar una colección autónoma de mapas del mundo antiguo. Sobre Abraham Ortelius, ver Meganck, 2017. Erudite eyes: friendship, art and erudition in the network of Abraham Ortelius (1527-1598). Brill, Leiden. 


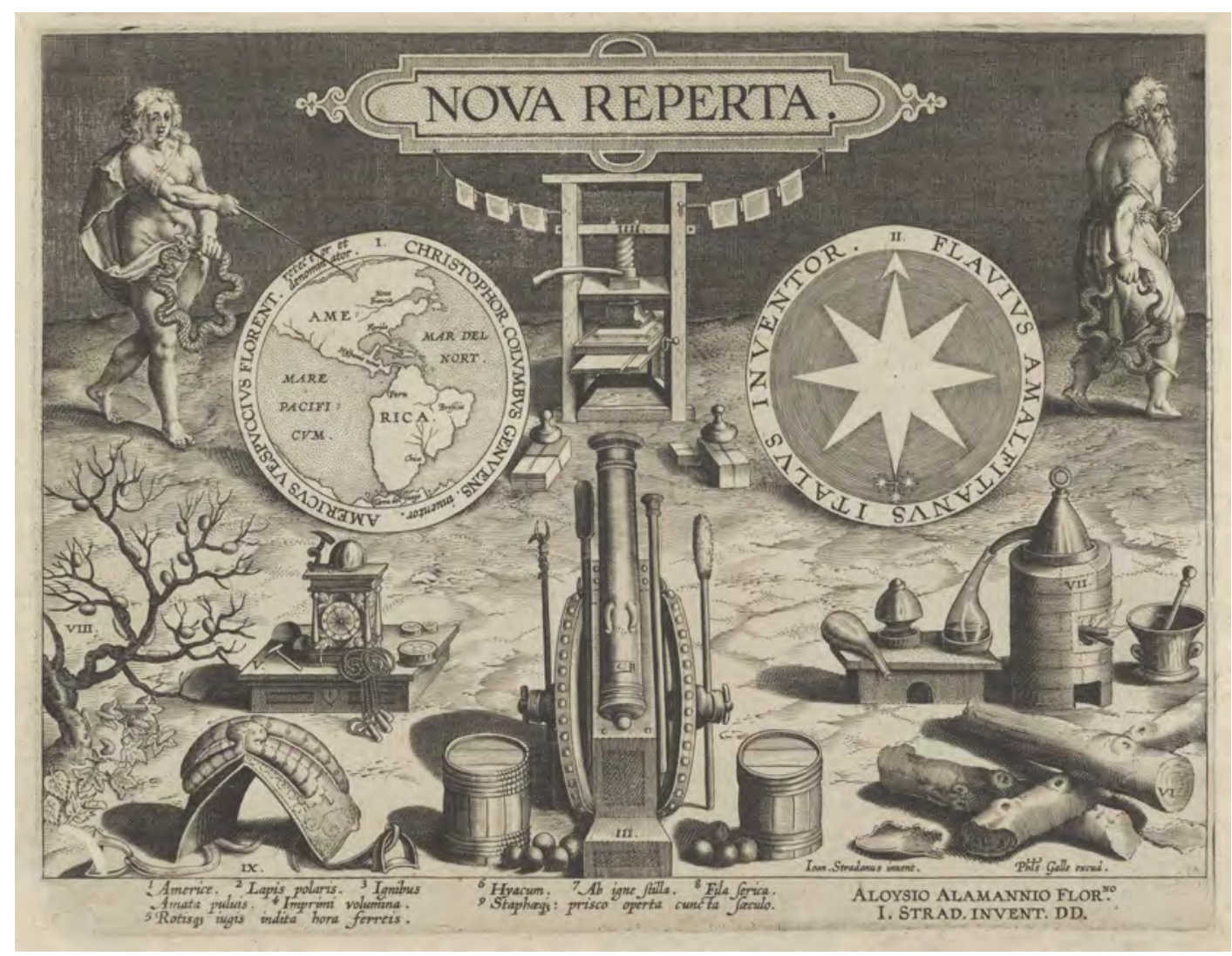

Fig. 1. Nova Reperta: Fronticepiece. New Inventions of Modern Times. Jan Galle (1600-1676), grabador; Jan Van der Straet (1523-1605), artista. Imagen de dominio público de la colección digital de la New York Public Library.

eso me llamo justamente VICTORIA, mis velas son alas, mi premio fue la gloria; mi lucha, el $m^{14}$. En el mapa, América está subdividida en meridional y septentrional. En el lado izquierdo, vemos los límites del Asia Oriental, con China, Japón, y las islas Filipinas. En el centro, el océano Pacífico aparece representado como lugar medible y navegable, un espacio que, si bien no había sido completamente explorado, es incluido dentro de los dominios de expansión de las Indias Occidentales o Nuevo Mundo exploradas por los castellanos.

En el mapa de Ortelius, la nao Victoria es un elemento fundamental dentro de la representación del océano Pacífico. El énfasis en el nombre de la nao y en la imagen de la diosa Nike sitúa el evento de la expedición dentro de un lenguaje propio

14 Ortelius, 1590. Theatrum Orbis Terrarum, Officina Plantiniana, Amberes. El poema en latín es como sigue: Prima ego velivolis ambivi cursibuas Orbem, Magellane de victoria y conquista militar. La nao ilustra a su vez la apertura del globo a la circunnavegación y sitúa en el primer plano de ese nuevo contexto de circulación oceánica el Pacífico. Publicada en 1590, la ilustración alegórica de la nao Victoria es propia del contexto transpacífico que emerge a finales del siglo XVI. A diferencia de los mapas producidos tras la expedición de Magallanes-Elcano, el Nuevo Mundo ya no es representado como una extensión oriental de Asia o como un obstáculo que impide llegar a las Molucas, sino como una masa de tierra firme que puede ser rodeada por las naos del mundo ibérico. Al situar en el centro de la representación un océano Pacífico navegable, el Nuevo Mundo emerge como un espacio de intercomunicación entre África, Europa y Asia.

novo te duce ducta freto, ambivi meritoque vocor VICTORIA: sunt mi Vela, alae; precium, Gloria; pugna, mare. 
Al igual que en el mapa de Ortelius y en el compendio de Luis Zapata, las crónicas que se escriben a finales del siglo XVI se refieren a la expedición de Magallanes-Elcano como evento que hizo posible abrir los mares a la navegación. Dentro de estas narrativas, cabe destacar la Historia del Reyno de la Gran China del agustino Juan González de Mendoza. En la Historia de Mendoza, China es el elemento central de una historia que se construye a partir de relatos de viajeros que llegan al extremo oriente desde el Nuevo Mundo. Publicado en Roma en 1585, el libro de Mendoza alcanzó la poco frecuente cifra de 38 ediciones en siete lenguas al final del siglo $\mathrm{XVI}^{15}$. La obra se divide en dos volúmenes, una primera parte dedicada a la sociedad, monarquía y antigüedades del mundo chino, y una segunda que incluye tres expediciones desde el Nuevo Mundo a China y Asia. El segundo libro, el cual ocupa dos tercios de la obra, es un compendio de viajes transpacíficos que narran la llegada de los castellanos a las Filipinas y China desde el Nuevo Mundo. Mendoza abre el segundo tomo aludiendo a la expedición de Miguel López de Legazpi como un evento que da continuidad a la expedición de Magallanes:

Gobernando el Reyno de Mexico Don Luys de Velasco Virrey y lugarteniente por el Catholico Rey don Phelippe nuestro señor, su Magestad le mando preparar una gruessa armada en el mar de Sur, y levantar los soldados para ella necesarios, y que la embiasse a descubrir las islas del Poniente de quien ya el famoso capitán

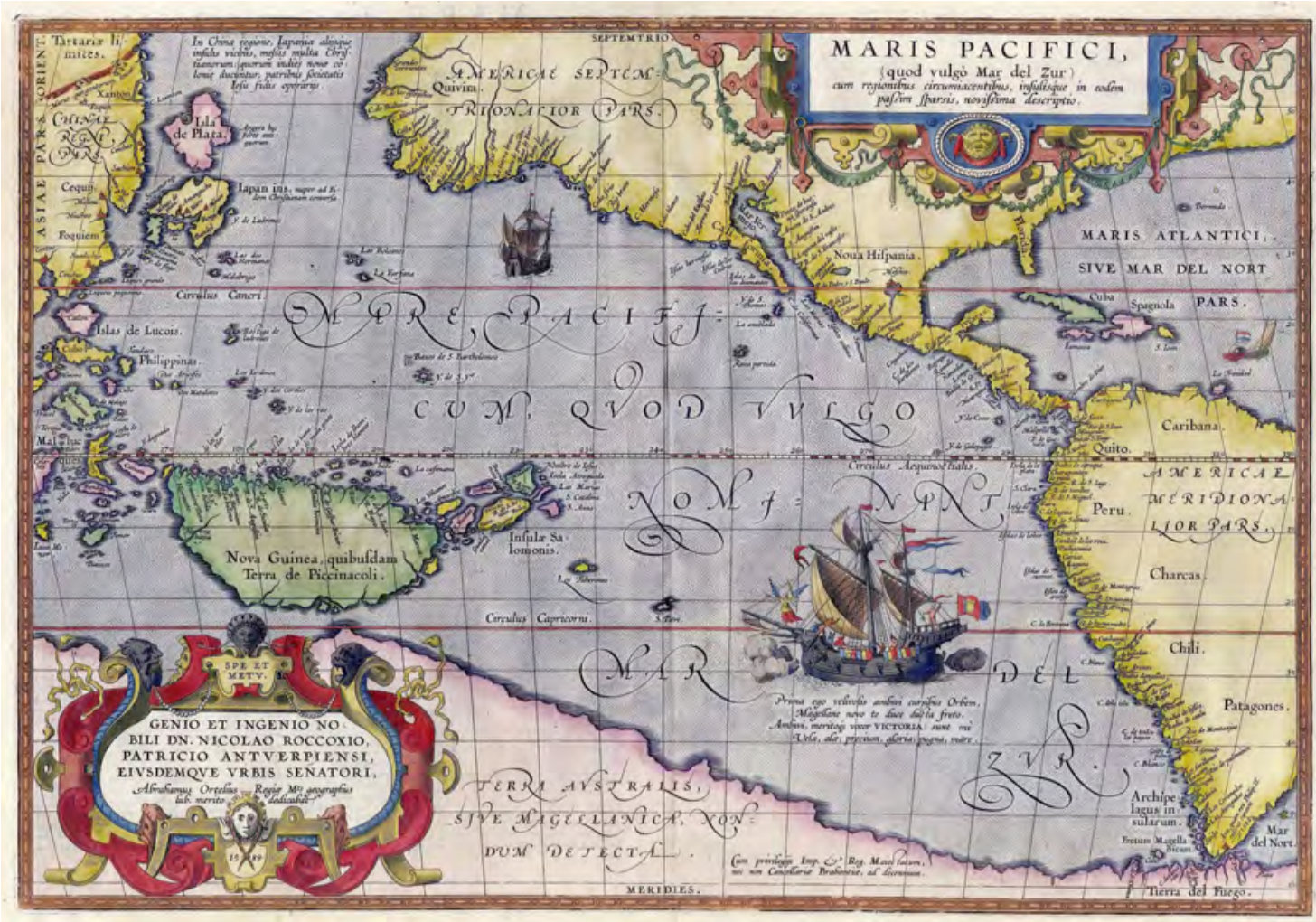

Fig. 2. Maris Pacifici. Abraham Ortelius, Theatrum Orbis Terrarum, 1590.

Página sin numerar en la edición de 1590; p. 6 en la edición de 1592.

15 Publicado inicialmente en español en Roma, el libro de Mendoza fue editado con modificaciones en Madrid (Querino Gerardo Flamenco, 1586). El libro fue además traducido en italiano (Roma, 1586), inglés (Londres, 1588), francés (París, 1588), latín (Frankfurt [¿1589?/1591]), holandés (Ámsterdam, 1595) y alemán (Leipzig, 1597). Para las citas y referencias, el artículo utiliza la edición de Madrid de Querino Gerardo Flamenco, 1586, en la que Mendoza corrige errores y añade nuevas secciones a la edición princeps de Roma (1585). 
Magallanes (quando con la nao Victoria dio vuelta a todo el mundo) avia dado noticia. Hizo el Virrey con mucho cuidado $y$ diligencia lo que su Magestad le mando, y puesta en orden la armada (que fu muy costosa) la hizo partir del puerto de la Navidad el año de $64^{16}$.

La asociación entre las expediciones de Magallanes-Elcano y de Legazpi es en la obra de Mendoza secuenciada como los dos eventos que cambian el transcurso de la historia del océano Pacífico. En lugar de hacer referencia a las historias del mundo portugués que se producen desde la segunda década del siglo XVI, la obra de Mendoza privilegia fuentes castellanas sobre el Pacífico y Asia ${ }^{17}$. Igualmente, en lugar de asociar China con el Catay de Marco Polo, Mendoza presenta su libro como una historia vinculada a la idea de "Nuevo Mundo"18. Aunque en el prefacio el agustino critica la ambición gloriosa con que los escritores modernos (aplicando historias antiguas a nuevos sujetos, para alcanzar perpetuo nombre) procuran inmortalizarse, Mendoza sugiere en su Historia que China es también un descubrimiento o un mundo nuevo nunca antes conocido por los antiguos.

En el Itinerario del Nuevo Mundo de Martín Ignacio de Loyola, franciscano que Mendoza conoció en Roma después del primer viaje de circunnavegación (1584) de los dos completados por el sobrino-nieto del fundador de la compañía de Jesús, Mendoza sitúa territorios de Asia dentro del Nuevo Mundo, conectando así la historia de Asia a la del Nuevo Mundo. A pesar de llevar por título Itinerario del Nuevo Mundo, el último libro de la Historia de Mendoza narra la vuelta que dio al mundo de Martín Ignacio en forma de itinerario, lo que en palabras de Mendoza significa decir (por vía de Itinerario) lo que el dicho Padre Custodio Fray Martin Ignacio me comunico de

16 Mendoza, 1586, op. cit., p. 121.

17 Aunque no publicadas hasta la mitad del siglo XVI en la colección de viajes de Ramusio, el mundo portugués produce obras sobre el extremo oriente a partir de la segunda década. Ver la Suma Oriental (ca. 1515) de Tomé Pires (1465-1524) y el Libro de Duarte Barbosa (1516) de Duarte Barbosa (1480-1521), quien también participó en la expedición de Magallanes.

18 En el prefacio al lector, Mendoza sugiere que la obra de Polo palabra y escripto havia visto y entendido en la vuelta que dio al mundo ${ }^{19}$. El Itinerario de Martín Ignacio recorre Canarias, Cuba y México antes de continuar a través del Pacífico su singladura hacia China, Malaca, la India y África para regresar finalmente a Roma. A su paso por las islas de los Ladrones (actuales islas Marianas) en el Pacífico, el libro de Martín Ignacio hace mención al viaje de Magallanes, describiendo las islas oceánicas que servían de parada entre México y las Filipinas para abastecer los galeones de agua: Los primeros que descubrieron estas islas fueron españoles que vinieron a ellas en compañía del famoso Magallanes, y no las conquistaron, porque sabian mas de navegar que de conquistar ${ }^{20}$. A continuación, el relato del viaje de Martín Ignacio narra la muerte de Magallanes y los motivos que hicieron posible que la nao Victoria completara la vuelta al mundo:

Despues de aver descubierto el estrecho (que hasta el dia de oy se llama de su sobrenombre) y llegado a la isla de Cebú, donde bautizaron a algunos de los naturales después en un combite, los mesmos isleños mataron a él (Magallanes), y a otros quarenta compañeros, que fue causa de que Sebastian de Guetaria, natural de Vizcaya, para escapar con la vida, se metiesse en una Nao que havia quedado del viaje, que después se llamo la Victoria, y con ella, y muy poca gente que le ayudó, con el favor de Dios, llegó a Sevilla, aviendo dado vuelta a todo el mundo, desde Oriente a Poniente, cosa que causó grande admiración, y al Emperador Carlos Quinto nuestro señor de gloriosa memoria, mas en particular, el cual después de haver hecho grandes mercedes al Sebastian de Guetaria, dio orden se tornasse a hazer nueva armada ${ }^{21}$.

trata de otra materia diferente a la de su libro: $y$ aunque Marco Polo en el largo viaje que hizo por Asia, pareze que quiere dar a conozer al mundo esta suerte de gente, ay quien no se certifica, si las cossas increybles que della quenta sean de los chinos o tártaros.

19 Mendoza, 1586, op. cit., p. 282.

20 Ibidem, p. 306.

21 Ibidem, p. 306v. 
En el Itinerario del Nuevo Mundo, la vuelta a "todo el mundo" desde oriente a poniente de la nao Victoria se inscribe dentro de la vuelta al mundo de Martín Ignacio, la cual aparece como un relato menor dentro de la Historia del Reyno de la Gran China. El viaje de Magallanes no solo representa en la narrativa de Martín Ignacio el evento que anticipa otras vueltas al mundo, sino que se proyecta como una forma de referir la experiencia del viaje dentro de un nuevo tipo de historia que, asociada con la idea de rodear el globo atravesando el Nuevo Mundo, comienza con la imagen de la nao Victoria. En el Itinerario del Nuevo Mundo de Martín Ignacio, rodear el Nuevo Mundo y rodear el mundo vienen a configurar una nueva perspectiva histórica. Tanto el viaje alrededor del mundo de Martín Ignacio de Loyola como el primer viaje de la nao Victoria representan acontecimientos asociados con un tipo de itinerario específico en el que la orientación nueva juega un papel decisivo a la hora de proyectar una nueva forma de escribir el presente. En ese sentido, las historias de Mendoza y de Martín Ignacio se sitúan dentro de un campo de experiencia de la historia ya consolidado desde el primer viaje de la nao Victoria hasta los viajes transpacíficos que tienen lugar en la segunda mitad del siglo XVI.

HISTORIAS ENTRELAZADAS EN LA CRÓNICA DE ANTONIO DE HERRERA Y TORDESILLAS

La primera vuelta al mundo que se inicia en 1519 y se completa con el regreso de la nao Victoria en septiembre de 1522 fue asociada desde sus inicios con otro evento que tuvo lugar durante esos mismos años de la tercera década del siglo XVI, la conquista de México. Desde la quinta Década de Pedro Mártir de Anglería hasta la Historia de Antonio de Herrera y Tordesillas, los cronistas insertaban ambos relatos en sus relatos intercalando los episodios de la navegación y conquista como dos historias que tenían un significado histórico análogo. En la narración de ambos eventos, una nueva forma de articular el presente en la historia emerge al producirse un tipo

22 Ballesteros, 1936. "Proemio", en Herrera y Tordesillas, Historia general de los hechos de los castellanos en las Islas y Tierra firme [sic] del Mar Océano. Prólogo y notas de Antonio Ballesteros-Beretta, Academia de la Historia, de relación nuevo entre el campo de experiencia y el horizonte de expectativa. Ahora bien, el campo de experiencia de la conquista y de la primera vuelta al mundo solo cristalizaría toda vez que las condiciones de posibilidad de ambas historias y de su conocimiento amplio pudieron ser proyectadas sobre un horizonte nuevo.

En 1601, Antonio de Herrera y Tordesillas (1559-1625) publica la Historia general de los hechos de los castellanos en las islas y tierra firme del mar océano, una suma de cuatro décadas sobre las navegaciones, conquistas y descubrimientos que tuvieron lugar entre 1492 y 1532. Nombrado cronista de Indias en la corte española en 1596, Herrera se encomendó la tarea de compilar fuentes y narrar los eventos del primer periodo de descubrimientos de los castellanos. La crónica de Herrera es la fuente más completa sobre la expedición de Magallanes-Elcano, al incorporar informaciones que vienen de las relaciones de Antonio Pigafetta, Joâo de Barros, Damião de Góis, Fernão Lopes de Castanheda, así como de numerosos documentos de archivo. Como indica el historiador Antonio Ballesteros en el prefacio a su edición de 1936, la parte de la crónica de Herrera que narra la expedición de Magallanes es la más valiosa porque el autor tuvo a su disposición varias historias de gran interés y consultó numerosas fuentes, como el diario del astrólogo Andrés de San Martín. Para Ballesteros, la obra de Herrera es tan detallada que supera la relación de Antonio Pigafetta en cuanto a la cantidad de fuentes y referencias relativas al viaje de la primera vuelta al mundo ${ }^{22}$. Además, como señala Xavier de Castro en la edición francesa del texto de Herrera sobre la expedición de Magallanes-Elcano, la crónica está particularmente bien documentada en la primera parte del viaje, hasta la muerte de Andrés de San Martín en Cebú, inspirándose a partir de ese momento de crónicas portuguesas y españolas ${ }^{23}$.

Al combinar fuentes producidas en diferentes momentos y por diferentes autores a lo largo del siglo XVI, Herrera integra un número amplio de experiencias dentro de una misma historia. Al erigirse como la referencia sobre el evento de la primera

Madrid.

23 de Castro, 2007. Le voyage de Magellan (1519-1522). La relation d'Antonio Pigafetta et autres témoignages. Chandeigne, Paris, p. 945. 
vuelta al mundo en el contexto de su publicación a principios del siglo XVII, la historia de la vuelta al mundo en la Historia General de Herrera se inscribe dentro de un marco histórico más amplio de sucesos que tienen lugar a lo largo de todo el siglo XVI. Sin embargo, el evento de la primera vuelta al mundo, así como el de la conquista de México, son dos acontecimientos sin los cuales los historiadores y cronistas no podían narrar el resto de historias que tuvieron lugar a lo largo del siglo XVI. Narrada hacia el final de la década segunda e inicios de la tercera, la historia de la expedición de Magallanes-Elcano aparece entrelazada en la Historia de Herrera con varios episodios de la conquista de México: ¿Cómo secuencia Antonio de Herrera estos acontecimientos de gran densidad histórica dentro de su crónica? ¿En qué medida la secuenciación de eventos tiene un impacto en la creación de un marco histórico que va a redefinir el campo de experiencia de la historia? ¿Cómo narrar a principios del siglo XVII el horizonte de expectativa que se abre después de la primera vuelta al mundo y de la conquista de México?

En la segunda década, Herrera comienza a relatar los eventos previos al viaje de Magallanes, sus desencuentros con Manuel I, la organización y partida de la expedición, la ruta atlántica hasta la travesía del Estrecho, dejando como episodio final la llegada a unas isletas pequeñas, i deshabitadas, que llamaron las Desventuradas, porque no hallaron Gente, consolidación, ni refresco alguno ${ }^{24}$. En este punto, Herrera interrumpe el transcurso del viaje, prosiguiendo con la historia de la guerra del cacique Urraca en Panamá para seguir después con la llegada de Pánfilo de Narváez a la Nueva España. Abandonados en mitad del Pacífico en unas desventuradas islas, el lector no vuelve a encontrarse con la expedición hasta los inicios de la Década III, donde los episodios de la conquista de México y la expedición de Magallanes-Elcano aparecen ya desde el frontispicio como los eventos clave del tercer volumen de la Historia General.

En la sucesión de capítulos, los sucesos se intercalan de manera que terminan por configurar una misma historia. En la lectura, la ausencia de transiciones más allá de los títulos de los capítulos tiene como consecuencia la creación de una narrativa lineal que proyecta la diversidad

24 Herrera y Tordesillas, 1726. Historia general de los hechos de los castellanos en las islas i tierra firme del de acontecimientos sobre un mismo espacio narrativo. Esta superposición de eventos aparece ya articulada desde el propio frontispicio (Fig. 3), donde la conquista de México y la expedición de Magallanes-Elcano son las historias que dan sentido a la tercera década. En la parte superior del frontispicio, vemos los retratos de Hernán Cortés y Hernando de Magallanes. Al lado del retrato de Hernán Cortés, se observa México-Tenochtitlan, mientras que Magallanes es acompañado por una imagen del Estrecho con cinco barcos al inicio de la travesía que abriría el paso hacia el Mar del Sur.

A continuación, la secuencia de viñetas procede de manera descendente, en el lado izquierdo vemos la serie de eventos que corresponden a la conquista de México, comenzando con el lugar en que fue preso Cuauhtémoc, la visita del rey de Michoacán a Hernán Cortés, la expedición de las Hibueras (Honduras), donde se muestra la ejecución de Cuauhtémoc, y una imagen final con la reedificación de México-Tenochtitlan. En la sección diestra, la secuencia muestra a Magallanes atravesando el Mar del Sur, una viñeta que ilustra la muerte de Magallanes peleando con los indios, y otra con la nao Victoria a su llegada a Sevilla después de rodear el mundo. Por último, el frontispicio introduce una viñeta final que muestra la disputa por la partición del mundo, una imagen que hace referencia a la controversia de las Islas Molucas y la discusión en torno a línea de demarcación negociada en el tratado de Zaragoza (1529), narradas hacia el final del volumen.

La década tercera sitúa los eventos de la conquista de México y de la vuelta al mundo de manera secuenciada, entrelazando episodios que en su origen y desenlace aparecen presentados dentro de una misma historia que se construye como una narrativa circular de apertura, conquista y dominio de los mares y del territorio, para concluir con la imagen de la reconstrucción del espacio y de la historia. Desde esa perspectiva narrativa, ambos acontecimientos marcan las transiciones, desplazamientos y batallas como momentos clave de una secuencia de eventos que terminan por reconfigurar un nuevo orden en el mundo. La historia se culmina con la imagen de la reedificación de México y la repartición del mundo, dando así a

mar oceano. Imprenta Real de Nicolás Rodiquez Franco, Madrid, Volumen 1, Década II, p. 237. 


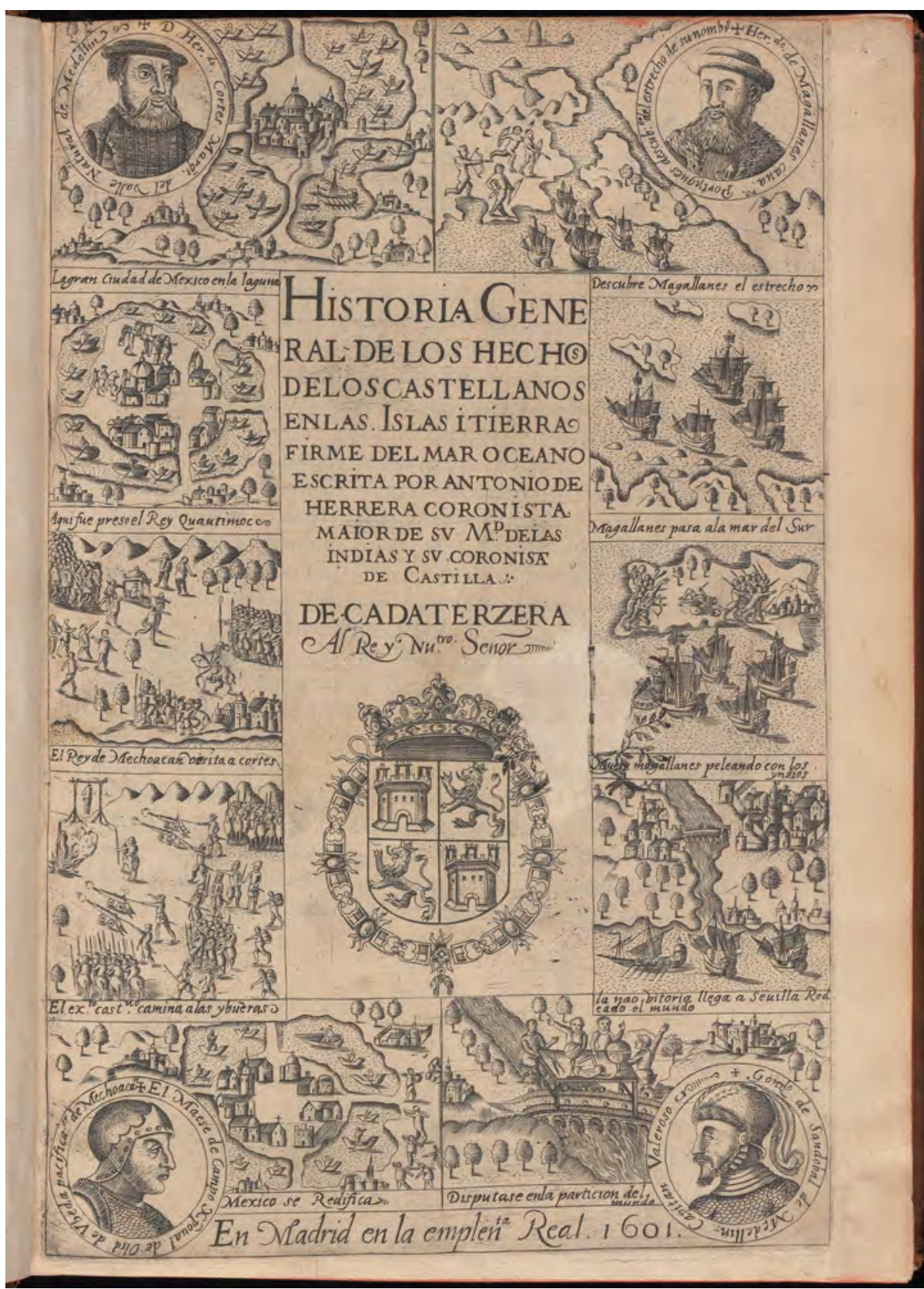

Fig. 3. Frontispicio de la Década Tercera de la Historia general de los hechos de los castellanos, de Antonio de Herrera y Tordesillas (1601).

Imagen en la colección digital de la Beinecke Rare Book \& Manuscript Library.

la narrativa una conclusión que se abre sobre un horizonte de expectativa nuevo: la reconstrucción y repartición de los territorios y los mares.

Si la conquista de México es narrada como el fin de un imperio y el inicio de otro, la vuelta al mundo también adquiere un sentido de apropiación y dominación en el que una forma de escribir el mundo termina para dar paso a un nuevo tipo de historia general del mundo. Como proyecta la narrativa de la tercera década, rodear el mundo implica abrazarlo e inscribirlo dentro de un nuevo tipo de historia. Para Herrera, la Historia general 
de los hechos de los castellanos es un preludio de una nueva historia mundo que el historiador calificaría en su segunda serie de crónicas con el apelativo de Historia general del mundo. En ese sentido, los hechos de los castellanos narrados entre 1492 y 1532 representan una suma de experiencias o hechos que terminan por configurar un tipo de historia mundo que cubre el reinado de Felipe II y que adquiere un carácter global al inscribirse dentro del campo de experiencia que se inicia con la tercera década.

$\mathrm{Si}$ rodear el globo es un hecho de los castellanos insólito en la tercera década, en la Historia general del mundo es una posibilidad continuamente abierta en el futuro. La posibilidad de rodear el mundo adquiere una nueva significación en la crónica de Herrera al representar no solo una forma de dominación y control imperial, sino al articularse como un nuevo régime d'historicité. Como observa Reinhart Koselleck: horizonte de expectativa es un término más adecuado que campo de expectativa. El horizonte es esa línea detrás de la cual se va a abrir un nuevo campo de experiencia del cual no se puede todavia tener conocimiento ${ }^{25}$. Si bien Herrera tiene un conocimiento amplio sobre el horizonte de expectativa que abriría la primera vuelta al mundo en el siglo XVI, la Historia general define el inicio de la tercera década como un momento de crisis de tiempo que transforma totalmente la comprensión del futuro y del pasado al iniciar un campo de experiencia nuevo sobre el cual no existía un conocimiento previo.

Desde esa perspectiva, la Historia de Herrera escrita hacia finales del siglo XVI se proyecta como una nueva forma de narrar las tres dimensiones temporales. El último episodio del viaje de Juan Sebastián Elcano, la llegada a Sevilla de la nao Victoria, tiene lugar el 6 de septiembre de 1522, un año y un mes después de la rendición de los mexicas (13 de agosto de 1521 ) relatada en la crónica en los capítulos VII y VIII del libro segundo de la tercera década. El capítulo VII narra cómo se ganó a México, i fue preso el Rei Quautimoc, terminando con las palabras que Cortés le dirigió a Cuauhtémoc después de su rendición e indicando que en ese momento acabó la Guerra, i el gran

25 Koselleck, 1990, op. cit., p. 313.

26 Herrera, 1726, op. cit., p. 53.
Imperio Mexicano ${ }^{26}$. El siguiente capítulo abre mencionando el día de la victoria y su relevancia histórica: fue esta victoria martes a trece de agosto, Día de San Hypolito, en cuya memoria se hace en México, cada Año, en tal Día, muy solemne fiesta ${ }^{27}$. La noticia de la victoria se sucede con la narración de los prodigios de la pérdida del imperio mexicano y la llegada de los doce frailes franciscanos liderados por Martín de Valencia.

Un nuevo tiempo ha comenzado y el pasado reciente que precede al acontecimiento de la conquista remite en la narrativa al mundo de las "antigüedades" mexicanas, las cuales son relatadas en la década tercera en los capítulos que siguen al final de la conquista. Al narrar las antigüedades mexicanas después de la conquista, Herrera antepone el nuevo orden político y temporal a un mundo antiguo descrito a posteriori y en ruptura con el presente. Dicho de otro modo, las antigüedades mexicanas son producto de la conquista, y no viceversa, al constituirse como los vestigios de la historia que dan vigencia al nuevo campo de experiencia de la historia que emerge con la conquista de México. En ese sentido, la Historia General de Herrera proyecta una nueva forma de hacer inteligible el pasado y las antigüedades del Nuevo Mundo a partir del evento de la conquista.

La llegada de la nao Victoria a Sevilla es narrada pocos capítulos después en el inicio de la Década III (capítulo IV, libro IV). En este caso, Herrera describe la ruta abierta por la nao como la mayor cosa que se haya visto jamás en la historia: y este camino que hizo esta nao fue la mayor y más nueva cosa que desde que Dios crió el primer hombre se vio ${ }^{28}$. Para Herrera, el horizonte de expectativa que se abre con el evento de la primera vuelta al mundo recae en la producción del "camino" o "itinerario" que hizo la nao, el cual viene a constituirse en el relato como el evento fundamental de la historia universal desde el inicio de la humanidad. Más que una hazaña del pasado narrada en el presente, la significación del viaje de la nao Victoria reside en la producción de un itinerario que va a transformar por completo modos de circulación y la forma en que se escribe la historia.

27 Ibidem, p. 54.

28 Ibidem, p. 116 
De la misma manera, los eventos que se narran en el inicio de la tercera década son presentados como victorias militares o conquistas que transforman el mundo, que anuncian el fin de un periodo antiguo y abren un nuevo tiempo marcado simbólicamente por la victoria, nombre que refiere igualmente a la conquista de México como a la expedición de Magallanes-Elcano. Si después de la conquista de México la crónica de Herrera inicia una serie de capítulos sobre las antigüedades mexicanas, la figura de Juan Sebastián Elcano y la vuelta al mundo es descrita como un evento sin antecedentes: pues fue el primero que rodeo el Mundo, no habiendo hasta entonces, entre los famosos antiguos, ni en los Modernos, ninguno que se le pueda comparar ${ }^{29}$.

En la Historia General, uno de los términos que más se repiten es la palabra tiempo, la cual articula transiciones y une en la narrativa eventos que tienen lugar en lugares distantes del globo: en ese mismo tiempo tuvo aviso Cortes, que habian llegado a la Veracruz quatro Navios de Santo domingo ${ }^{30}$, abre Herrera en el capítulo VI, o en este mismo tiempo, por algunas informaciones que el Emperador havia tenido de diversos Cosmógrafos, se hallaba, que fácilmente se podía embiar a descubrir las Tierras del Catayo Oriental ${ }^{31}$. Estas continuas actualizaciones temporales construidas a través de deícticos sirven de enlace entre los múltiples momentos $y$ acciones que pueblan los capítulos de la crónica. En ese sentido, los sucesos narrados en la crónica de Herrera no son particularidades desconectadas que convergen de manera fortuita en una temporalidad histórica, sino que el entrelazamiento es el recurso que da sentido a una configuración narrativa que consigue anudar eventos que tuvieron lugar en regiones distantes del globo. Como observó el historiador William Prescott en el siglo XIX, ese continuo cruce de eventos lejanos entre sí suponía una molesta elección narrativa que impedía al lector moderno centrarse en la acción que transcurre dentro de cada historia narrada en la crónica de Herrera:

La obra está dispuesta en forma de anales, y los variados y multiplicados

\footnotetext{
29 Ibidem, p. 111.

Ibidem, p. 9

Ibidem, p. 143.
}

sucesos de que trata, están todos sistemados en el órden cronológico, $y$ aunque acaecidos en regiones muy distantes, y disímbolos, todos caminan pari passu. A causa de esta mala disposición, se ve obligado el lector a interrumpir a cada instante el hilo de los sucesos y a saltar de una escena a otra muy distinta, sin tener tiempo de contemplar completamente ninguna. La paciencia se agota, y la atención se cansa con esas ojeadas parciales y vagas, en vez de satisfacerse al ver desarrollada hábilmente una narración continua bien compaginada. Este es el grave defecto inherente a un plan que se funda servilmente en la cronología ${ }^{32}$.

Aunque para William Prescott el mayor defecto de la Historia General es su servilismo a la cronología, la adopción de un principio narrativo que anuda eventos distantes entre sí es el artificio que permite dar un sentido homogéneo al presente en la crónica de Herrera. Si bien la crónica obliga al lector a saltar constantemente de una escena a otra, el recurso narrativo al entrelazamiento acerca al lector a una nueva forma de consciencia global que emerge como resultado de una "distante y disímbola" experiencia narrativa del presente. En lugar de privilegiar el espacio como elemento que cohesiona y une eventos distantes, la crónica teje las historias con un hilo que remite continuamente a un presente fabricado a partir de nudos de hechos que aparecen dispersos a través del globo. La consciencia global emerge así estrechamente pegada a un presente que encuentra siempre en la primera vuelta al globo completada por la nao Victoria en 1522 la primera referencia con la cual comenzar el relato de la expansión del mundo ibérico.

\section{CONCLUSIONES}

Los episodios de la conquista y la primera vuelta al mundo configuran en la Historia General el advenimiento de un momento de crisis de tiempo en la historia. Hacia finales del siglo XVI y

32 Prescott, 1844. Historia de la conquista de México, impreso por Ignacio Cumplido, México, p. 419. 
principios del XVII, Herrera aborda ambos eventos como detonantes que abren una brecha en el tiempo al ser narrados como historias que producen una nueva manera de articular las tres dimensiones temporales de pasado, presente y futuro. En las crónicas de finales del siglo XVI, la adopción de un campo de experiencia producido en relación con la posibilidad de rodear el mundo hace que la historia se oriente hacia un tiempo presente en ruptura con el pasado. Desde esa perspectiva, las historias que narran la expedición de Magallanes-Elcano en ese contexto resitúan la posibilidad de dar la vuelta al mundo dentro de un campo de experiencia de la historia más amplio a través de eventos que fueron sedimentando el relato de la expansión del mundo ibérico a lo largo del siglo XVI.

Para los historiadores de finales del siglo XVI, las referencias generadas previamente dentro de ese campo de experiencia que emerge después de la vuelta al globo de la nao Victoria no son solo vestigios o fuentes con las que volver a escribir el mismo relato. Al contrario, el conjunto de fuentes sobre el viaje de Magallanes-Elcano producidas a lo largo del siglo XVI se inserta dentro de un campo de experiencia entrelazado que las crónicas vinculan para dar un sentido homogéneo al presente histórico. En tanto que acontecimiento que hizo posible abrir un horizonte de expectativa nuevo, el relato de la circunnavegación de la nao Victoria representaba un momento de crisis de tiempo a partir del cual se debía anudar toda la historia de la expansión del mundo ibérico. Desde diferentes perspectivas y con diferentes propósitos, las historias de Juan González de Mendoza y Antonio de Herrera y Tordesillas integran los eventos de principios de la tercera década dentro de otras historias que, si bien tienen lugar a posteriori, dan sentido retrospectivamente a un momento de crisis de tiempo que redefine las relaciones y vínculos que establecen entre sí la escritura de la historia y el orden del tiempo.

A partir del momento narrativo de la primera vuelta al mundo, las historias anudan la especificidad histórica de un nuevo presente al articular todo un campo de experiencia amplio que remite siempre a la posibilidad de rodear el mundo que se abre con el viaje de la nao Victoria. Desde esa perspectiva, la emergencia de una consciencia global no es un elemento que afecta únicamente a la comprensión del espacio y de la geografía, sino también a la escritura de la historia. Esta consciencia se produce como resultado de un campo de experiencia que se va sedimentando a lo largo del siglo XVI hasta adquirir su máxima expresión hacia finales de siglo, cuando rodear el mundo no representaba ya una hazaña incomprensible del presente, sino un "hecho de los castellanos" en el pasado reciente y una posibilidad tangible abierta en el horizonte de una nueva forma de narrar el tiempo presente de la historia.

Como observaba Koselleck es la tensión entre la experiencia y la expectativa que suscita de una manera diferente en cada caso soluciones nuevas que engendran el tiempo histórico ${ }^{33}$. Al superar todo horizonte de expectativa previo, la primera vuelta al mundo de la nao Victoria hizo posible y necesario volver a escribir el tiempo presente de la historia. Por ese motivo, los historiadores de finales del siglo XVI y principios del XVII no podían sino narrar de nuevo el regreso de la nao Victoria de su largo viaje cuando querían evocar la emergencia de una consciencia global sobre la que se comenzó a articular una nueva forma de relación entre el presente, el pasado y el futuro.

\section{BIBLIOGRAFÍA}

Bénat-Tachot, L. (2018). Les tracés du monde: réflexions sur les voies d'une première globalisation 1519-1579. E-Spania: Revue électronique d'études hispaniques médiévales, 30.

Castro, X de. (2007). Le voyage de Magellan (1519-1522). La relation d'Antonio Pigafetta et autres témoignages. Paris: Chandeigne.

Eisenstein, E. L. (2011). Divine Art, Infernal Machine. Philadelphia: University of Pennsylvania Press.

Grafton. A. (1992). New Worlds, Ancient Texts: The Power of Tradition and the Shock of Discovery. Cambridge: Harvard University Press.

Hartog, F. (2015). Regimes of Historicity, Presentism and Experience of Time. New York: Columbia University Press.

Koselleck, R. (1990). Le futur passé, Contribution à la sémantique des temps historiques. Paris: Editions de l'EHESS.

33 Koselleck, 1990, op. cit., p. 314. 
Meganck, TK. (2017). Erudite eyes: friendship, art and erudition in the network of Abraham Ortelius (15271598). Brill, Leiden.

Prescott, W. (1844). Historia de la conquista de México. México: impreso por Ignacio Cumplido.

Valdovinos, R. (2017). Un régime d'historicité face au Nouveau Monde. E-Spania: Revue électronique d'études hispaniques médiévales 28.

\section{FUENTES}

Barbosa, D. (1918-1921). The book of Duarte Barbosa: an account of the countries bordering on the Indian Ocean and their inhabitants (2 volúmenes). Londres: Hakluyt Society.

Acosta, J. (2006). Historia Natural y Moral de las Indias. Edición de Edmundo O'Gorman. México: Fondo de Cultura Económica.

Herrera y Tordesillas, A. (1601). Primera parte de la Historia general del Mundo, de XVII años del tiempo del señor don Felipe II el Prudente, desde el año de 1554 hasta el de 1570. Madrid: Luis Sánchez a costa de Juan de Montoya, mercader de libros.

Herrera y Tordesillas, A. (1601-1726). Historia general de los hechos de los castellanos en las islas i tierra firme del mar oceano (Volumen 1: Década II; Volumen 2: Década III). Madrid: Imprenta Real de Nicolás Rodiquez Franco.

Herrera y Tordesillas, A. (1601). Historia general de los hechos de los castellanos en las Islas y Tierra Firme del Mar Oceano / escrita por Antonio de Herrera...; en quatro decadas desde el año de 1492 hasta el de
1531. Madrid: Imprenta Real, por Juan Flamenco.

Herrera y Tordesillas, A. (1934-1957). Historia general de los hechos de los castellanos en las Islas y Tierra Firme [sic] del Mar Océano / por Antonio de Herrera. Prólogo y notas de Antonio Ballesteros-Beretta. Madrid: Academia de la Historia.

López de Gómara, F. (1922). Historia General de las Indias, Tomo I. Madrid: Calpe.

Mendoza, J. G. (1586). Historia de las cosas mas notables ritos y costumbres del gran reyno de China: sabidas assi por los libros de los mesmos chinas, como por relación de religiosos y otras personas que han estado en el dicho Reyno. Con un intinerario del nuevo mundo. Madrid: Querino Gerardo Flamenco.

Ortelius, A. (1579). Parergon Sive Veteris Geographia. Amberes: Officina Plantiniana.

Ortelius, A. (1590). Theatrum Orbis Terrarum. Amberes: Officina Plantiniana.

Pigafetta, A. (1899). Primer viaje alrededor del mundo relato escrito por el caballero Antonio Pigafetta. Madrid: Imprenta de Fortanet.

Pires, T. (1944). The 'Suma Oriental' of Tomé Pires: An Account of the East, from the Red Sea to China, 2 vols. Edición de Armando Cortesão. London: printed for the Hakluyt Society.

Transilvanus, M. (1523). De Moluccis insulis, itemq[ue] alijs pluribus mira[n]dis, quæ nouissima Castellanorum nauigatio sereniss. imperatoris Caroli. V. auspicio suscepta, nuper inuenit. Coloniæ: In æedibus Eucharij Ceruicorni.

Zapata, L. (1931). Miscelánea: silva de casos curiosos. Madrid: Compañía Ibero-Americana de Publicaciones. 